\title{
A population-based study of the effect of the HFE C282Y and H63D mutations on iron metabolism
}

\author{
Omer T Njajou ${ }^{1}$, Jeanine J Houwing-Duistermaat ${ }^{1}$, Richard H Osborne ${ }^{2}$, Norbert Vaessen ${ }^{1,3}$, \\ Jeanette Vergeer $^{1}$, Jan Heeringa ${ }^{1}$, Huibert AP Pols ${ }^{1,3}$, Albert Hofman ${ }^{1}$ and \\ Cornelia M van Duijn ${ }^{1}$
}

\author{
${ }^{1}$ Department of Epidemiology and Biostatistics, Erasmus Medical Centre, Rotterdam, The Netherlands; ${ }^{2}$ Center for \\ Genetic Epidemiology, The University of Melbourne, Melbourne, Australia; ${ }^{3}$ Department of Internal Medicine, Erasmus \\ Medical Centre, Rotterdam, The Netherlands
}

The C282Y and H63D mutations in the HFE gene are important causes of hemochromatosis. In the elderly, these mutations might be associated with increased morbidity because of the lifelong accumulation of iron. In a population-based sample of the elderly, we determined the value of genotyping for HFE mutations to screen for subclinical hemochromatosis. HFE genotype frequencies were determined in a random group of 2095 subjects (55 years and over). In this random group, we selected within the six genotype groups a total of $\mathbf{3 4 2}$ individuals and measured their serum transferrin saturation, iron and ferritin levels. We also estimated the heritability and parameters needed to evaluate screening, including the sensitivity, specificity, positive and negative predictive values (PPV, NPV) of HFE genotypes. Iron parameters were significantly increased in subjects homozygous, heterozygous or compound heterozygous. The effect of the mutations was more pronounced in men than in women. For the H63D mutation, an allele dose effect was observed. The HFE gene explained about $5 \%$ of the variability in serum iron indices. The PPV for hemochromatosis for the C282Y homozygous was $100 \%$ in men and $67 \%$ in women. The NPV of the wild-type allele was $97 \%$ for both men and women. The sensitivity of both mutations was $70 \%$ for men and $52 \%$ for women and the specificity was $62 \%$ for men and $64 \%$ for women. Our study shows that the HFE C282Y and H63D are determinants of iron parameters in the elderly and will be effective in detecting individuals at high risk of hemochromatosis. However, when screening based on these two mutations, some individuals with subclinical hemochromatosis will be missed.

European Journal of Human Genetics (2003) 11, 225-231. doi:10.1038/sj.ejhg.5200955

Keywords: hemochromatosis; iron; elderly; screening; HFE; C282Y; H63D; penetrance

\section{Introduction}

Hereditary hemochromatosis is a disease characterized by iron accumulation in the tissue of several organs including the liver, heart, pancreas, pituitary and joints. ${ }^{1}$ Iron

\footnotetext{
*Correspondence: Dr CM van Duijn, Department of Epidemiology and Biostatistics, Erasmus Medical Centre, PO Box 1738, 3000 DR Rotterdam, The Netherlands. Tel: +31 10408 7394; Fax: +31 10408 9406; E-mail: Duijn@epib.fgg.eur.nl

Received 17 June 2002; revised 17 December 2002; accepted 19 December 2002
}

deposition may result in a wide range of common conditions such as arthritis, diabetes, myocardial infarction, stroke and cancer. ${ }^{2,3}$ Several mutations involved in the pathogenesis of hemochromatosis have been described. ${ }^{4}$ The two most common are the $845 \mathrm{G} \rightarrow \mathrm{A}$ (C282Y) transition and the $187 \mathrm{C} \rightarrow \mathrm{G}$ (H63D) transversion in the HFE gene on chromosome $6 .^{5}$ Most of our knowledge about the genotype-phenotype relationship is derived from studies of patients diagnosed with hereditary hemochromatosis. Over $80 \%$ of all patients are homozygous for the $\mathrm{C} 282 \mathrm{Y}$ mutation, suggesting that this is by 
far the most common cause of hereditary hemochromatosis. $^{5,6}$ Further, compound heterozygotes, that is, carriers of both the HFE C282Y and H63D mutations, have been found to be at increased risk of hereditary hemochromatosis. ${ }^{7}$ However, these findings are based on series of patients derived from families with hereditary hemochromatosis. In the general population, subclinical hemochromatosis can exist undetected for many years. Recently, Beutler et $a l,{ }^{8}$ reported that in subjects older than 26 years, less than $1 \%$ of $\mathrm{C} 282 \mathrm{Y}$ homozygotes develop frank clinical hemochromatosis while $30 \%$ had subclinical hemochromatosis based on serum transferrin saturation. Although this was a large study, there have been several shortcomings and violations of principles and concepts of epidemiologic studies concerning study design, subject recruitment and generalizability of results. Apart from us, Poullis et al, ${ }^{9}$ Cox et al, ${ }^{10}$ Allen et al ${ }^{11}$ and Basset et al, ${ }^{12}$ to name but a few, have raised serious objections to this study and the interpretation of the data.

Since iron accumulation can be prevented by phlebotomy, there is increasing interest in genetic screening for genetically determined high-risk groups based on HFE. Although there is a debate about the relevance of screening for hemochromatosis, important parameters such as the sensitivity, specificity, positive and negative predictive values (PPV, NPV) of HFE genotyping have not been investigated in a population-based study. Increased levels of serum iron, ferritin and transferrin saturation have been found in subjects homozygous or heterozygous for the C282Y and H63D mutations as well as compound heterozygotes. $^{8,13,14,16,18}$ However, it is not clear to what extent the relation between the $\mathrm{C} 282 \mathrm{Y}$ or $\mathrm{H} 63 \mathrm{D}$ heterozygosity and iron status can be explained by subjects who are compound heterozygotes. Further, a significant additive effect on iron status of the H63D mutation was found, ${ }^{14}$ suggesting that individuals heterozygous or homozygous for the common H63D mutation may be at increased risk for hemochromatosis and related disorders.

Up until now, most population-based studies have targeted relatively young populations. ${ }^{8,14,19}$ The mean age of the largest study ${ }^{8}$ conducted to date in Caucasians was 56.9 years. Owing to their subtle effect on iron status, the effect of heterozygosity may be pronounced in older people. Iron accumulation is likely to be more pronounced in elderly men. We know of only one study in the elderly that investigated the effect of heterozygosity for HFE $\mathrm{C} 282 \mathrm{Y}$ or $\mathrm{H} 63 \mathrm{D}$ on iron levels. ${ }^{20}$ However, this study included only women who are, prior to menopause, relatively protected from iron accumulation due to menstruation. The aim of this investigation was to study the contribution of the HFE C282Y and H63D mutations to serum iron indices in an elderly population (55 years and older) and to evaluate the usefulness of genetic screening to identify subjects with subclinical hemochromatosis.

\section{Materials and methods Participants}

The present investigation was conducted within the Rotterdam Study, a population-based study of subjects aged 55 years and over living in a suburb of Rotterdam, The Netherlands. Baseline examination took place in 1990. Details on this cohort study are described elsewhere. ${ }^{21}$ Briefly, information on current health status and medical history was obtained by means of a structured interview using a standardized questionnaire. Participants attended the research center for several clinical and laboratory tests. Fasting blood samples were collected by venipuncture and serum was kept frozen until analysis. In total, 7983 people participated in the Rotterdam Study (response rate $78 \%$ ). From each participant, written informed consent was obtained. The study was approved by the medical ethics committee of the Erasmus Medical Centre. From the total cohort genotyped, we randomly selected a group of 2095 subjects and estimated the frequency of the HFE C282Y and H63D mutations. Several iron parameters were compared across genotypes. To maximize the power of the study, subjects with rare genotypes were oversampled. After the subjects were genotyped, we measured the serum transferrin saturation, iron and ferritin levels in a total of 342 individuals selected within the six genotype groups based on HFE C282Y and H63D, that is, those without any mutation (the wild-type homozygous $\mathrm{Wt} / \mathrm{Wt}, n=74$ ), the H63D heterozygotes (H63D/Wt, $n=73$ ), the C282Y heterozygotes (C282Y/Wt, $n=71)$, the H63D homozygotes (H63D/H63D, $n=60)$, the compound heterozygotes (C282Y/H63D, $n=51)$ and all available C282Y homozygotes (C282Y/C282Y, $n=8$ ). Five samples with evidence of hemolysis were excluded from the study. A transferrin saturation level above $45 \%$ is proposed as a cutoff value for the diagnosis of hemochromatosis in population-based screening. ${ }^{22}$ Although not a direct measure of iron storage in the body, transferrin saturation $>45 \%$ is used as the 'golden standard' for population-based screening, and at this threshold, 98\% of iron overloaded subjects are identified. $^{22}$ To verify the relevance in our population, serum liver enzymes, aspartate amino-transferase (AST) and alanine amino-transferase (ALT) were compared between subjects with transferrin saturation less and greater than $45 \%$.

\section{Laboratory analysis}

Genomic DNA was extracted from frozen buffy coat using the salting-out protocol fragments of DNA amplified by the polymerase chain reaction (PCR) using oligonucleotides primers described previously. ${ }^{5}$ The $25 \mu \mathrm{l}$ PCR reaction tube contained $100 \mathrm{ng}$ of each primer, $2.5 \mu \mathrm{l}$ of $10 \times$ PCR buffer, $2.5 \mathrm{~mm}$ dNTP, $50 \mathrm{~mm} \mathrm{MgCl}_{2}, 5 \mathrm{U} / \mu \mathrm{l}$ Ampli Taq Gold and $2 \mu \mathrm{l}(\sim 50 \mathrm{ng})$ DNA. We carried out $15 \mathrm{~min}$ of initial denaturation at $94^{\circ} \mathrm{C}, 35$ cycles of $30 \mathrm{~s}$ at $94^{\circ} \mathrm{C}, 30 \mathrm{~s}$ at $55^{\circ} \mathrm{C}$ and $1.5 \mathrm{~min}$ at $72^{\circ} \mathrm{C}$. Restriction digestion was 
performed directly on the PCR products by the addition of $0.1 \mathrm{U} / \mu \mathrm{l}$ Sna BI (Perkin-Elmer) for codon 282 or $0.1 \mathrm{U} / \mu \mathrm{l}$ Dpn II (Perkin-Elmer) for codon 63 and incubating overnight at $37^{\circ} \mathrm{C}$. The products were electrophoresed on a $3 \%$ agarose gel containing ethidium bromide in the presence of a $1 \mathrm{~kb}$ DNA standard. Control samples of known status (normozygous, heterozygous and homozygous) for each mutation were included at the PCR stage. Amplification with the primer for codon 282 produces a PCR product of $390 \mathrm{bp}$, which will not digest the wild type and will digest the mutant to produce 276 and $113 \mathrm{bp}$ pieces. Amplification with the primer for codon 63 produces a PCR product of $208 \mathrm{bp}$, which digests the wild types to produce $138 \mathrm{bp}$ and $70 \mathrm{bp}$ pieces but will not digest the mutant.

Iron status was assessed in stored serum samples $\left(-80^{\circ} \mathrm{C}\right)$. Serum transferrin saturation was measured by immunoturbidimetric assay using the Tina-quant kit (Roche), serum iron was measured by immuno(chemiluminescence) assay using the Roche/Hitachi 717 kit (Roche) and serum ferritin was measured by colorimetric assay using the Elecsys (Roche). AST and ALT were measured according to the protocols of the International Federation of Clinical Chemistry (IFCC). ${ }^{23}$

\section{Statistical analysis}

Genotype frequencies were estimated by gene counting and allele frequencies calculated from genotype frequencies. Population means of iron indices were estimated by taking the sum of the means of serum iron indices for the genotype weighted with the genotype frequency. To study the relation between iron parameters and HFE genotypes, linear regression models were fitted for males and females separately. In these models, the effect of the compound heterozygotes was included as an interaction between the C282Y and H63D mutations. More parsimonious models were considered by assuming additive effects for the two mutations. The models assume that the effect in subjects who are homozygous is twice that of those who are heterozygous. Additivity was tested for each mutation by comparing the model with the genotypes as additive effect (coding 0 for WtWt, 1 for the heterozygotes and 2 for the homozygotes) to the model including the genotypes as a categorical variable (codominant model). The models were compared by using the $F$-statistic. Heritability (percentage variance) of iron parameters due to HFE mutations was computed based on the final model and using the population frequencies of the various genotypes. Using the population-based frequencies of the mutations by genotype and the prevalence of subclinical hemochromatosis, the positive predictive value (PPV: the proportion of people with a positive test who have the disease), the negative predictive value (NPV: the proportion of people with a negative test who do not have the disease), the sensitivity (the probability that the test correctly classifies people with preclinical disease as positive) and specificity (the probability that the test classifies as negative those who will not have the disease) were estimated as described elsewhere. ${ }^{24,25}$

\section{Results}

Table 1 shows the findings of the genotyping of the HFE gene for the $\mathrm{C} 282 \mathrm{Y}$ and $\mathrm{H} 63 \mathrm{D}$ mutations in the random population-based series of 2095 subjects. The genotypes are ordered by frequency; the $\mathrm{Wt} / \mathrm{Wt}$ was the most common HFE genotype (63.1\% in women) and the C282Y/C282Y genotype was the most rare genotype ( $0.2 \%$ in men). Genotype frequencies were in Hardy-Weinberg equilibrium proportions for both men and women. There was only a small nonsignificant decrease in the frequency of the $\mathrm{C} 282 \mathrm{Y}$ and $\mathrm{H} 63 \mathrm{D}$ mutation by age. In women, the allele frequency of the $\mathrm{C} 282 \mathrm{Y}$ mutation varied from $6.4 \%$ in those aged 55-64 years to $6.2 \%$ in those 75 years and older, while in men the $\mathrm{C} 282 \mathrm{Y}$ allele frequency varied from 6.0 to $5.0 \%$. For the H63D mutation, the frequency of the genotypes also did not vary significantly by age group. The frequency for those 55-64 was 14\% compared to $19 \%$ for those 75 years and over.

Table 2 shows the population prevalence of subclinical hemochromatosis and the weighted means of serum transferrin saturation, iron and ferritin for men and women. The population prevalence of hemochromatosis was higher in men compared to women. We observed that men had higher levels of serum transferrin saturation, iron and ferritin compared to women. The mean (SD) age was 67.12 (6.59) years for men and 67.08 (6.32) years for women. When testing the effect of each mutation on the iron parameters, additivity for $\mathrm{C} 282 \mathrm{Y}$ was rejected, whereas additivity for H63D could not be rejected for all outcomes (data not shown). When testing for interaction between the two HFE mutations, a significant interaction between the $\mathrm{C} 282 \mathrm{Y}$ and $\mathrm{H} 63 \mathrm{D}$ alleles was found for serum transferrin saturation $(P=0.004)$, for serum iron $(P=0.003)$ and for serum ferritin $(P=0.006)$ (data not shown). This suggests that the effect of the two mutations in compound heterozygotes is higher than that predicted

Table 1 Frequency of HFE genotypes in a populationbased random sample of 2095 subjects

\begin{tabular}{lcc}
\hline Genotype & Men & Women \\
\hline $\mathrm{Wt} / \mathrm{Wt}^{\mathrm{a}}$ & $604(60.6)$ & $693(63.1)$ \\
$\mathrm{H} 63 \mathrm{D} / \mathrm{Wt}$ & $250(25.1)$ & $241(21.9)$ \\
$\mathrm{C} 282 \mathrm{Y} / \mathrm{Wt}$ & $99(9.9)$ & $107(9.7)$ \\
$\mathrm{H} 63 \mathrm{D} / \mathrm{H} 63 \mathrm{D}$ & $29(2.9)$ & $30(2.7)$ \\
$\mathrm{C} 282 \mathrm{Y} / \mathrm{H} 63 \mathrm{D}$ & $13(1.3)$ & $23(2.1)$ \\
$\mathrm{C} 282 \mathrm{C}$ /C282Y & $2(0.2)$ & $6(0.4)$
\end{tabular}

${ }^{a} \mathrm{Wt}=$ wild type (absence of mutation). Values are numbers (\%) of individuals. 
from the effect in heterozygotes. Table 3 shows the effect of HFE mutations on iron parameters. Serum transferrin saturation, iron and ferritin levels were significantly higher $(P<0.001)$ for those homozygous for the C282Y mutation in men as well as women compared to those homozygous for the wild type. There was a significant interaction between sex and C282Y homozygosity for all iron parameters, suggesting a more pronounced effect in men. Compound heterozygosity was associated with a significant effect on all serum iron indices except for ferritin in women. Also for the compound heterozygotes, there was a significant difference in effect between men and women. The H63D mutation was associated with significantly increased levels of serum transferrin and iron in men and women. Heterozygosity for the $\mathrm{C} 282 \mathrm{Y}$ mutation was not

Table 2 Prevalence of subclinical hemochromatosis and weighted means (SD) of serum iron parameters

\begin{tabular}{lcc}
\hline & $\begin{array}{c}\text { Men } \\
n=167\end{array}$ & $\begin{array}{c}\text { Women } \\
n=170\end{array}$ \\
\hline $\begin{array}{l}\text { Transferrin saturation (\%) } \\
\text { Iron }(\mu \mathrm{mol} / \mathrm{l})\end{array}$ & $29.32(12.36)$ & $26.28(10.12)$ \\
Ferritin $(\mathrm{ng} / \mathrm{ml})$ & $17.47(6.28)$ & $16.03(5.38)$ \\
Prevalence of subclinical & $205.46(152.84)$ & $155.11(113.25)$ \\
hemochromatosis $(\%)$ & 12.42 & 8.10 \\
\hline
\end{tabular}

significantly associated with serum iron, ferritin and transferrin saturation when analysing men and women separately. The effects were very similar in men and women. When combining men and women, we observed a significant association of the C282Y heterozygous with serum transferrin saturation $(P<0.03$, data not shown).

Together, the HFE genotypes explained about $6 \%$ of the variability of serum transferrin saturation in men and 5\% in women, whereas the proportion of variability of serum iron and ferritin was less than 5\% in men and women. A total of 21 men (13\%) and 14 women (8\%) had serum transferrin saturation over $45 \%$. When using the cutoff point of $45 \%$ to define subjects with subclinical hemochromatosis, all men (100\%) and $67 \%$ of the women homozygous for $\mathrm{C} 282 \mathrm{Y}$ showed levels of serum transferrin saturation above the cutoff. None of the subjects were known by their treating physician with a diagnosis of hemochromatosis. However, we found significantly increased ALT (16.4 vs 18.6 IU, $P=0.02)$ and AST (19.7 vs 21.0 IU, $P=0.08$ ) levels when comparing subjects with transferrin saturation lower or higher than $45 \%$. Table 4 shows the PPV, NPV, sensitivity and specificity of HFE genotypes. The PPV for subclinical hemochromatosis varied from $100 \%$ in men homozygous for $\mathrm{C} 282 \mathrm{Y}$ to $2.8 \%$ in women heterozygous for the H63D, while the sensitivity varied from $3.6 \%$ for men homozygous for

Table 3 Means (+SE) serum iron indices by HFE genotype

\begin{tabular}{|c|c|c|c|c|c|c|}
\hline Genotype & $\begin{array}{c}\text { Men } \\
n\end{array}$ & & $P$ value & $\begin{array}{c}\text { Wome } \\
n\end{array}$ & & $P$-value ${ }^{a}$ \\
\hline \multicolumn{7}{|c|}{ Serum transferrin saturation (\%) } \\
\hline $\mathrm{Wt} / \mathrm{Wt} \mathrm{t}^{\mathrm{b}}$ & 36 & $27.41(24.26-30.56)$ & Reference & 38 & $24.41(21.65-27.17)$ & Reference \\
\hline $\mathrm{H} 63 \mathrm{D} / \mathrm{Wt}$ & 37 & $31.16(25.51-36.80)$ & $0.003^{\mathrm{c}}$ & 36 & $32.65(23.45-33.60)$ & 0.001 \\
\hline $\mathrm{C} 282 \mathrm{Y} / \mathrm{Wt}$ & 36 & $34.93(26.78-43.05)$ & 0.11 & 35 & $27.86(25.26-40.03)$ & 0.1 \\
\hline $\mathrm{C} 282 \mathrm{Y} / \mathrm{H} 63 \mathrm{D}$ & 23 & $31.18(23.35-39.00)$ & $<0.001$ & 28 & $33.08(20.93-34.80)$ & $<0.001$ \\
\hline $\mathrm{H} 63 \mathrm{D} / \mathrm{H} 63 \mathrm{D}$ & 33 & $43.95(27.20-45.63)$ & $0.003^{c}$ & 27 & $43.29(17.53-33.50)$ & $0.001^{\mathrm{c}}$ \\
\hline C282Y/C282Y & 2 & 73.87 (55.74-99.99) & $<0.001$ & 6 & $24.41(32.50-54.09)$ & $<0.001$ \\
\hline \multicolumn{7}{|c|}{ Serum iron $(\mu \mathrm{mol} / \mathrm{l})$} \\
\hline $\mathrm{Wt} / \mathrm{Wt}$ & 36 & $16.67(14.97-18.35)$ & Reference & 38 & $15.22(13.68-16.75)$ & Reference \\
\hline $\mathrm{H} 63 \mathrm{D} / \mathrm{Wt}$ & 37 & $18.46(15.44-21.50)$ & $0.009^{c}$ & 36 & $17.10(14.28-19.91)$ & $0.004^{\mathrm{C}}$ \\
\hline $\mathrm{C} 282 \mathrm{Y} / \mathrm{Wt}$ & 36 & $20.27(15.90-24.64)$ & 0.42 & 35 & $18.98(14.87-23.08)$ & 0.27 \\
\hline $\mathrm{C} 282 \mathrm{Y} / \mathrm{H} 63 \mathrm{D}$ & 23 & $17.69(13.50-21.89)$ & $<0.001$ & 28 & $16.52(13.94-20.36)$ & 0.007 \\
\hline $\mathrm{H} 63 \mathrm{D} / \mathrm{H} 63 \mathrm{D}$ & 33 & $24.43(16.65-26.55)$ & $0.009^{c}$ & 27 & $18.65(11.03-19.90)$ & $0.004^{c}$ \\
\hline $\mathrm{C} 282 \mathrm{Y} / \mathrm{C} 282 \mathrm{Y}$ & 2 & $33.50(23.77-43.23)$ & $<0.001$ & 6 & $21.84(15.84-27.83)$ & 0.004 \\
\hline \multicolumn{7}{|c|}{ Serum ferritin $(\mathrm{ng} / \mathrm{ml})$} \\
\hline $\mathrm{Wt} / \mathrm{Wt}$ & 36 & $187.56(128.58-246.53)$ & Reference & 38 & $145.52(104.42-186.62)$ & Reference \\
\hline $\mathrm{H} 63 \mathrm{D} / \mathrm{Wt}$ & 37 & $227.65(120.05-333.23)$ & 0.09 & 36 & $154.52(79.00-230.03)$ & 0.61 \\
\hline $\mathrm{C} 282 \mathrm{Y} / \mathrm{Wt}$ & 36 & $267.74(115.51-419.94)$ & 0.96 & 35 & $163.52(53.58-273.44)$ & 0.16 \\
\hline $\mathrm{C} 282 \mathrm{Y} / \mathrm{H} 63 \mathrm{D}$ & 23 & $189.67(43.30-336.03)$ & $<0.001$ & 28 & $190.12(89.99-293.24)$ & 0.19 \\
\hline $\mathrm{H} 63 \mathrm{D} / \mathrm{H} 63 \mathrm{D}$ & 33 & $388.40(173.88-518.51)$ & $0.09^{c}$ & 27 & $189.60(17.26-254.92)$ & $0.61^{c}$ \\
\hline C282Y/C282Y & 2 & $665.51(326.59-1004.42)$ & 0.001 & 6 & $357.17(196.55-517.78)$ & 0.001 \\
\hline
\end{tabular}

${ }^{a} P$-value of difference compared to wild type.

${ }^{b} \mathrm{Wt}=$ wild type.

${ }^{\mathrm{c}}$ One degree of freedom. 
C282Y to 37\% for men heterozygous for H63D. For all HFE genotypes, the PPV was $10 \%$ for men and 5\% for women, the sensitivity was $70 \%$ for men and $52 \%$ for women, and the specificity was $62 \%$ for men and $64 \%$ for women. The NPV for men as well as women was over $97 \%$.

\section{Discussion}

In this population-based sample of the elderly, $0.3 \%$ were homozygous and 10\% were heterozygous for the C282Y and 3\% were homozygous and 23\% were heterozygous for the H63D mutation. These frequencies are very similar to those observed in younger populations ${ }^{26,27}$ and in a sample of elderly men. ${ }^{28}$ We did not find evidence for a significant decrease in the frequency of the HFE C282Y mutation or H63D mutation with age, suggesting that these mutations may remain putative risk factors for chronic diseases thoughout late age. Serum transferrin saturation and serum iron levels were significantly increased in those homozygotes or compound heterozygous for $\mathrm{C} 282 \mathrm{Y}$ as well as H63D in both men and women. Subjects heterozygous for the H63D or C282Y mutation showed a modest but statistically significant increase in serum transferrin when combining the findings of men and women (adjusted for age and sex). In those homozygous and compound heterozygotes, the effect of HFE was significantly stronger in men. Although the H63D mutation has been regarded as nonfunctional, our results show that the H63D is associated with increased serum iron and transferrin saturation independent of the presence of the C282Y allele. This finding is in line with previous reports of large populationbased studies. ${ }^{14,19,29}$ Serum ferritin showed the weakest association with the two HFE mutations studied. A significantly higher serum ferritin was observed only for

Table 4 Positive and negative predictive values, sensitivity and specificity of HFE genotypes

\begin{tabular}{lcccc}
\hline Genotype & $\begin{array}{l}\text { Men } \\
n=167\end{array}$ & & $\begin{array}{l}\text { Women } \\
n=170\end{array}$ & \\
& $\begin{array}{l}\text { NPV } \\
(\%)\end{array}$ & $\begin{array}{l}\text { Specificity } \\
(\%)\end{array}$ & $\begin{array}{l}\text { NPV } \\
(\%)\end{array}$ & $\begin{array}{l}\text { Specificity } \\
(\%)\end{array}$ \\
Wt/Wt & 97.2 & 62 & 97.4 & 64 \\
& & & & \\
& PPV & Sensitivity & PPV & Sensitivity \\
& $(\%)$ & $(\%)$ & $(\%)$ & $(\%)$ \\
H63D/Wt & 8.1 & 36.6 & 2.8 & 18.2 \\
C282Y/Wt & 8.3 & 14.8 & 2.9 & 8.3 \\
H63D/H63D & 12.1 & 6.3 & 7.4 & 5.9 \\
C282Y/H63D & 34.8 & 8.1 & 17.9 & 11.1 \\
C282Y/C282Y & 100 & 3.6 & 66.7 & 7.9 \\
All HFE & 9.8 & 69.5 & 4.7 & 51.5 \\
genotypes & & & & \\
\hline
\end{tabular}

$N P V=$ negative predictive value; $P P V=$ positive predictive value. the C282Y homozygotes (men and women) and compound heterozygous men. This is for a large part explained by the fact that serum ferritin has by far the largest standard deviation. Therefore, the power to assess a relation between the HFE mutations and serum ferritin was very low.

In this study, we considered patients with serum transferrin levels above $45 \%$ as having subclinical hemochromatosis. Earlier studies have shown that using this cutoff point, $98 \%$ of patients with hereditary hemochromatosis may be detected. ${ }^{22}$ None of the patients with a serum transferrin saturation level over $45 \%$ in our study was known by themselves or their treating physician with a clinical diagnosis of hemochromatosis. However, we found increaed levels of liver enzymes in those with serum transferrin saturation above $45 \%$. Using serum transferrin saturation above $45 \%$, the PPV is high (100\%) for men homozygous for $\mathrm{C} 282 \mathrm{Y}$ as well as women homozygous for the C282Y mutation (67\%). Thus, screening for C282Y homozygosity is helpful to identify high-risk groups. These carriers identified do have a high risk of diseases. These findings appear to be at odds with those of Beutler et al, ${ }^{8}$ who reported that less than $1 \%$ of subjects $\mathrm{C} 282 \mathrm{Y}$ homozygous develop frank clinical hemochromatosis. Several shortcomings of this study were already raised by others. ${ }^{9-13}$ The contradictory finding of Beutler et al, ${ }^{8}$ may be related to the case definition of hemochromatosis. As pointed out by Poullis et al, ${ }^{9}$ accurate definition of the phenotype is a key issue in estimating penetrance. When studying subclinical hemochromatosis, our findings and those of Beutler et $a l^{8}$ are similar. Moreover, Beutler et al studied only the C282Y mutation in a subset of the 152 homozygotes found. That this may have introduced bias in their study is supported by the fact that the prevalence of diabetes was significantly reduced in carriers of the C282Y mutation $(P=0.02)$. This finding is biologically implausible and most likely resulted from selection bias. Finally, several studies including ours have shown that the H63D mutation is also an important mutation in the pathology of hemochromatosis. As these subjects are included in their 'control' group, the power of the study of Beutler et al may have been diminished.

Although our study suggests that screening for the C282Y mutation may be effective to detect subjects with increased transferrin saturation, whether the HFE C282Y and H63D mutations can be used to detect all or most persons with subclinical hemochromatosis in the population depends not only on the PPV but also on the sensitivity and the specificity. We found that screening for hemochromatosis based on HFE genotypes has a sensitivity of $70 \%$ for men and $53 \%$ for women and a specificity of $62 \%$ for men and $64 \%$ for women. These values suggest that many subclinical cases will be undetected when screening based on the HFE genotypes. At first, this observation is at odds with the findings that $85 \%$ 
of patients with hemochromatosis are explained by homozygosity for the $\mathrm{C} 282 \mathrm{Y}$ mutation. However, these findings are based on patients with hereditary forms of iron disease, ${ }^{6,30}$ and the number of patients with a genetic (HFE) origin may therefore be high. The situation is very different in the general population. Although our study suggests that the HFE C282Y and H63D mutations are determinants of physiological iron levels, the HFE genotypes explained no more than $5 \%$ of the variability in serum iron indices. This observation is in agreement with estimates derived from a sample of twins ${ }^{14}$ and points towards the existence of factors other than HFE genotypes that account for the serum levels of iron. These may concern genetic as well as environmental factors. Also, there is strong linkage disequilibrium in the HLA region where the HFE gene is located and other closely linked genes may modify the phenotype. ${ }^{15}$

Our findings in the general elderly population suggest that the value for screening for high iron based on HFE genotypes is limited in that only a small percentage of subjects with elevated levels of iron will be detected. However, the aim of a population-based screening is to identify at an early stage individuals at risk of developing serious iron overload, to prevent organ damage. Although not all patients may be found, the implication for those who are found are high despite the controversy of the role of HFE in disease. Indeed the study of Beutler et $a l^{8}$ does show that increased serum iron and transferrin saturation are associated with liver pathology and diabetes. This implies that reducing iron load in carriers is relevant. If anything can be learned from the population study of Beutler et al and ours, it is that translating genetic findings into preventive strategies in public health is not as straightforward as anticipated.

In conclusion, our study shows that the HFE C282Y and $\mathrm{H} 63 \mathrm{D}$ are common mutations in the elderly. At late age, these mutations are still determinants of serum transferrin, iron and ferritin. Heterozygosity for the C282Y and H63D mutations is associated with small effects on serum iron parameters. Although the PPV is high in C282Y homozygotes, the sensitivity is low. Thus, screening will be helpful in identifying individuals at high risk of developing frank iron loading, but a large number of subjects with increased transferrin saturation will be undetected.

\section{Acknowledgements}

We thank Mrs W Luijten for HFE genotyping and Dr HJM Smeets for providing reference samples. This study was supported by the Netherlands Organization for Scientific Research (NWO), the Netherlands Diabetes Foundation, the NESTOR Stimulation Program for Geriatric Research in The Netherlands (Ministry of Health and Ministry of Education) and the Municipality of Rotterdam. Dr Osborne's position has been funded by a National Health and Medical Research Council of Australia Public Health Fellowship.

\section{References}

1 Bhavnani M, Lloyd D, Bhattacharyya A, Marples J, Elton P, Worwood M: Screening for genetic hemochromatosis in blood samples with raised alanine aminotransferase. Gut 2000; 46: 707-710.

2 Powell LW, Jazwinska E, Halliday JW: Primary iron overload; in Brock JH, Halliday JW, Pippard MJ, Powell LW (eds): Iron metabolism in health and disease. London, WB Saunders, 1994; pp 227-270.

3 Edwards CQ, Griffen LM, Goldgar D et al: Prevalence of hemochromatosis among 11605 presumably healthy blood donors. N Engl J Med 1988; 318: 1355-1362.

4 De Villiers JN, Hillerman R, Loubser L, Kotze JM: Spectrum of mutations in the HFE gene implicated in hemochromatosis and porphyria. Hum Mol Genet 1999; 8: 1517-1522.

5 Feder JN, Gnirke A, Thomas W et al: A novel MHC class I-like gene is mutated in patients with hereditary hemochromatosis. Nat Genet 1996; 13: 399-408.

6 Jouanolle AM, Gandon G, Jezequel P et al: Haemochromatosis and HLA-H. Nat Genet 1996; 14: 251-252.

7 de Valk B, Witlox RS, van der Schouw YT, Marx JJ: Biochemical expression of heterozygous hereditary hemochromatosis. Eur $J$ Intern Med 2000; 11: 317-321.

8 Beutler E, Felitti VJ, Koziol JA, Ho NJ, Gelbart T: Penetrance of $845 \mathrm{G} \rightarrow \mathrm{A}(\mathrm{C} 282 \mathrm{Y})$ HFE hereditary haemochromatosis mutation in the USA. Lancet 2002; 359: 211-218.

9 Poullis A, Moodie SJ, Maxwell JD: Clinical haemochromatosis in HFE mutation carriers (Letter). Lancet 2002; 360: 411.

10 Cox T, Rochette J, Camaschella C, Walker A, Robson K: Clinical haemochromatosis in HFE mutation carriers (Letter). Lancet 2002; 360:412.

11 Allen KJ, Warner B, Delatycki MB: Clinical haemochromatosis in HFE mutation carriers (Letter). Lancet 2002; 360: 412-413.

12 Basset ML, Wilson SR, Cavanaugh JA: Penetrance of HFE-related hemochromatosis in perspective. Hepatology 2002; 36: 500-503.

13 Rossi E, Bulsara MK, Olynyl JK, Cullen DJ, Summerville L, Powell LW: Effect of hemochromatosis genotype and lifestyle factors on iron and red cell indices in a community population. Clin Chem 2001; 47: 202-208.

14 Whitfield JB, Cullen LM, Jazwinska EC et al: Effects of HFE C282Y and H63D polymorphism and polygenic background on iron stores in a large community sample of twins. Am J Hum Genet 2000; 66: 1246-1258.

15 Porto $\mathrm{G}$ et al: Clinical and genetic heterogeneity in hereditary haemochromatosis: association between lymphocyte counts and expression of iron overload. Eur J Haematol 2001; 67: 110-118.

16 Bulaj ZJ, Griffen LM, Jorde LB, Edwards CQ, Kushner JP: Clinical and biochemical abnormalities in people heterozygous for hemochromatosis. N Engl J Med 1996; 335: 1799-1805.

17 Datz C, Haas T, Rinner H, Sandhoffer F, Patsch W, Paulweber B Heterozygosity for the $\mathrm{C} 282 \mathrm{Y}$ mutation in the hemochromatosis gene is associated with increased serum iron, transferrin saturation, and hemoglobin in young women: a protective role against iron deficiency? Clin Chem 1998; 44: 2429-2432.

18 Adams PC: Prevalence of abnormal iron studies in heterozygotes for hereditary hemochromatosis: an analysis of 255 heterozygotes. Am J Hematol 1994; 45: 146-149.

19 Olynyk JK, Cullen DJ, Aquilia S, Rossi E, Summerville L, Powell LW: A population based study of the clinical expression of the hemochromatosis gene. N Engl J Med 1999; 341: 718-724.

20 Rossi E, Olynyk JK, Cullen DJ, Papadopoulos G, Bulsara M Summerville L, Powell LW: Compound heterozygous hemochromatosis genotype predicts iron and erythrocyte indices in women. Clin Chem 2000; 46: 162-166.

21 Hofman A, Grobbee DE, de Jong PT, van den Ouweland FA: Determinants of diseases and disability in the elderly: the Rotterdam Elderly Study. Eur J Epidemiol 1991; 4: 403-422.

22 McLaren CE et al: Distribution of transferrin saturation in an Australian population: relevance to the early diagnosis of hemochromatosis. Gastroenterology 1998; 114: 543-549. 
23 Bergmeyer HU, Horder M, Rej R: International Federation of Clinical Chemistry (IFCC) Scientific Committee Analytical Section: approved recommendation on IFCC methods for the measurements of catalytic concentration of enzymes. J Clin Chem Clin Biochem 1986; 24: 481-510.

24 Holtzman NA, Marteau TM: Will genetics revolutionize medicine? N Engl J Med 2000; 343: 141-144.

25 Wald NJ, Hackshaw AK, Frost CD: When can a risk factor be used as a worthwhile screening test? BMJ 1999; 319: 1562-1565.

26 Baer DM, Simons JL, Staples RL: Hemochromatosis screening in asymptomatic ambulatory men 30 years of age and older. Am J Med 1995; 98: 464-468.
27 Cullen LM, Summerville L, Glassick TV, Crawford DHG, Powell LW, Jazwinska EC: Neonatal screening for the hemochromatosis defect. Blood 1997; 90: 4236-4237.

28 Willis G, Wimperis JZ, Smith KC, Fellows IW, Jennnings BA: Haemochromatosis gene C282Y homozygotes in an elderly male population. Lancet 1999; 354: 221-222.

29 Burt MJ. The significance of haemochromatosis gene mutations in the general population: implications for screening. Gut 1998; 43: 830-836.

30 Jazwinska EC, Cullen LM, Busfield F et al. Haemochromatosis and HLA-H. Nat Genet 1996; 14: 249-251. 